Lymphology 52 (2019) 18-24

\title{
IMPACT OF BODY FAT AND OBESITY ON TISSUE DIELECTRIC CONSTANT (TDC) AS A METHOD TO ASSESS BREAST CANCER TREATMIENT-RELATED LYMIPHEDEMA (BCRL)
}

\author{
H. Mayrovitz
}

College of Medical Sciences, Nova Southeastern University, Davie, Florida, USA

\section{ABSTRACT}

Obesity is linked to the risk of breast cancer and treatment-related lymphedema (BCRL). Thus, knowledge of how obesity, or more specifically total body fat percentage $(T B F)$ and body mass index (BMI), affect measurements that are used to detect or track lymphedema is clinically important. Tissue dielectric constant (TDC) is one measure used to help characterize lymphedema features, detect its presence, and assess treatment-related changes. The goal of this research was to determine the extent to which TDC values depend on TBF and BMI. TDC was measured on both forearms $(2.5 \mathrm{~mm}$ depth) in 250 women (18-72 years) along with TBF (impedance, $50 \mathrm{KHz}$ ). TBF was $12.2 \%$ $54.4 \%$ (median $=29.3 \%$ ) and BMI was $14.7 \mathrm{Kg} / \mathrm{m}^{2}-44.3 \mathrm{Kg} / \mathrm{m}^{2}$ (median=22.6 $\mathrm{Kg} / \mathrm{m}^{2}$ ). $T D C$ values and interarm ratios were compared between subgroups that had TBF and BMI values in lower vs. upper quartiles. Subjects in the upper quartile had slightly lower TDC values (1.3 TDC units, $p<0.01)$ that was at most a 5\% differential. Contrastingly, TDC interarm ratios were not dependent on TBF or $B M I$ levels. These findings suggest that when tracking lymphedema changes using the TDC method, treatment-related or temporal changes in a woman's TBF or BMI are unlikely to significantly impact TDC values or their interarm ratios.
Keywords: lymphedema, body fat, body mass index, breast cancer, tissue dielectric constant tracking lymphedema, measuring lymphedema

Obesity is linked to breast cancer risk (1-4) and obesity is also linked to the risk of treatment-related lymphedema (BCRL) (5-7). Because of these associations, knowledge as to how obesity, or more generally total body fat percentage (TBF) and body mass index (BMI), affects measures that are used to detect or track lymphedema is of clinical importance. One such measure is the tissue dielectric constant (TDC) that is increasingly used as a tool to help characterize lymphedema features $(8,9)$, detect its presence $(10,11)$, and assess treatment-related changes (12-16). Furthermore, such measurements show practicality in a range of conditions (17-20) and are used to study applied aspects of skin physiology (21-23).

The underlying physics and principle of operation of this technology are well described in the literature $(24,25)$ but there has been no systematic study of the potential impact of TBF or BMI on TDC values and especially how changes in either of these during a course of treatment or simply over time may effect TDC. Because local TDC values are directly related to water content of tissue, a greater relative contribution of low water content 
tissues such as fat suggest that patients with higher TBF would have TDC values that are lower than those measured in patients with less TBF. Further, if there were such an inverse relationship between TDC and TBF then when persons under treatment either gain or lose TBF, sequential TDC values used to track lymphedema changes would be confounded by the TBF dependency in an unknown way. Thus, our specific aim was to investigate this issue by determining if there is a significant dependency of absolute TDC values or their interarm ratios on ranges of $\mathrm{TBF}$ and $\mathrm{BMI}$ in women of a wide age range.

\section{METHODS}

\section{Participants}

A total of 250 adult females participated as volunteer subjects after signing an approved Nova Southeastern University (NSU) institutional review board informed consent. Subjects were recruited from medical students, staff, university faculty, and others via word of mouth. To be included subjects needed to: 1) be 18 years or older, 2) have no history of arm trauma that resulted in sustained swelling, 3) be free of any skin condition or open wound on their arm, 4) not be taking any medication known to impact edema, and 5) not have diabetes. Ages of participants ranged from 18 to 72 years with a mean \pm SD age of $29.8 \pm 11.7$ years and a median of 25.0 years. Body mass index (BMI) for the group ranged from 14.7 to $44.3 \mathrm{Kg} / \mathrm{m}^{2}$ with a mean $\pm \mathrm{SD}$ of $23.9 \pm 5.0 \mathrm{Kg} / \mathrm{m}^{2}$ and a median value of 22.6 $\mathrm{Kg} / \mathrm{m}^{2}$. Using the standard BMI classification, the percentage of subjects that were obese was $12 \%$, overweight was $19.6 \%$, normal weight was $69 \%$, and underweight was $8.4 \%$.

\section{Measurements}

TDC values were measured in triplicate on both forearms while subjects were resting supine with arms at their sides with palms up. The measurement site was on the anterior forearm five $\mathrm{cm}$ distal to the antecubital fossa. This is a frequently used clinically-related TDC measuring site $(9,11,23,26,27)$. All TDC measurements were made with the MoistureMeterD (Delfin, Kuopio, Finland) using a probe whose measurement includes tissue to an effective depth of $2.5 \mathrm{~mm}$ below the skin surface. This probe depth is the most frequently used in studies employing this technology. Temperature and relative humidity of the room in which measurements were done was $22.9 \pm 1.6^{\circ} \mathrm{C}$ and $54.0 \pm 6.1 \%$ across all experiments. Skin temperature, averaged between dominant and nondominant arms, measured with an infrared thermometer (Exergen, Watertown Main, Model DX501-RS), was 32.1 \pm $1.2^{\circ} \mathrm{C}$.

The physics and basic operating principles of TDC measurements are well described in the literature $(24,28,29)$. Briefly, the probe acts as an open-ended coaxial transmission line through which a $300-\mathrm{MHz}$ signal is transmitted. Reflected energy depends on the tissue's complex permittivity, that depends on the signal frequency and tissue dielectric constant (real part of the permittivity). At $300 \mathrm{MHz}$, conductance contributes little to permittivity, so TDC is mainly determined by water molecules (free and bound). As a reference, distilled water at $32^{\circ} \mathrm{C}$ would have a dielectric constant of about 76 .

After TDC measurements, subjects sat up for 5 minutes, removed their footwear and stood on a scale for about 10 seconds while gripping a handle-electrode to measure weight and body composition via bioimpedance at $\mathbf{5 0}$ $\mathrm{KHz}$ (InnerScan Body Composition Monitor, Tanita model BC558). Parameters measured were total body fat percentages (TBF), total body water percentages (TBW) and dominant and nondominant arm fat percentages (AFP). Values were determined by device proprietary algorithms based on the measured impedances. 
Analyses

The distribution of each parameter was tested for Normality using the Shapiro-Wilk Test (SWT). Results showed that the distribution of forearm TDC values was not significantly different from Normal (SWT significance $\mathbf{0 . 2}$ ) for dominant, nondominant arms or their combined values. The combined TDC distribution shown in Fig. 1A. In contrast, TBF, TBW, and AFP were rejected as being Normally distributed (SWT significances 0.001 to .003). The TBF distribution is shown in Fig. 1B. Thus, subsequent tests for differences in dominant-to-nondominant sides for TDC values were based on paired t-tests whereas all other comparisons were based on the nonparametric Wilcoxon test. With all tests a p-value $<0.05$ was taken as a statistically significant difference. To estimate effects of TBF on TDC, subjects with TBF values below and above the TBF median were first compared and then subjects with TBF values in the upper and lower quartiles were compared with nonparametric Mann-Whitney U tests.

\section{RESULTS}

\section{Fat and TDC Values}

Figure 1 demonstrates the distribution of forearm absolute TDC values and also the total body fat percentage (TBF) distribution. The TDC values for each subject in Fig. 1 are the average of dominant and nondominant side TDC values. Averages, medians, and standard deviations corresponding to all parameters measured are reported in Table 1.

Arm fat percentage (AFP) of the nondominant arm was slightly greater than for the dominant arm $(p<0.001)$. For the full group, the AFP of the nondominant arm was 0.67 \pm 1.63 greater than the dominant arm. This corresponds to a $2.2 \%$ greater fat percentage. When considering subjects within lower and upper quartiles of TBF, the percentage difference in fat between dominant and nondominant arms was greater for the lower quartile
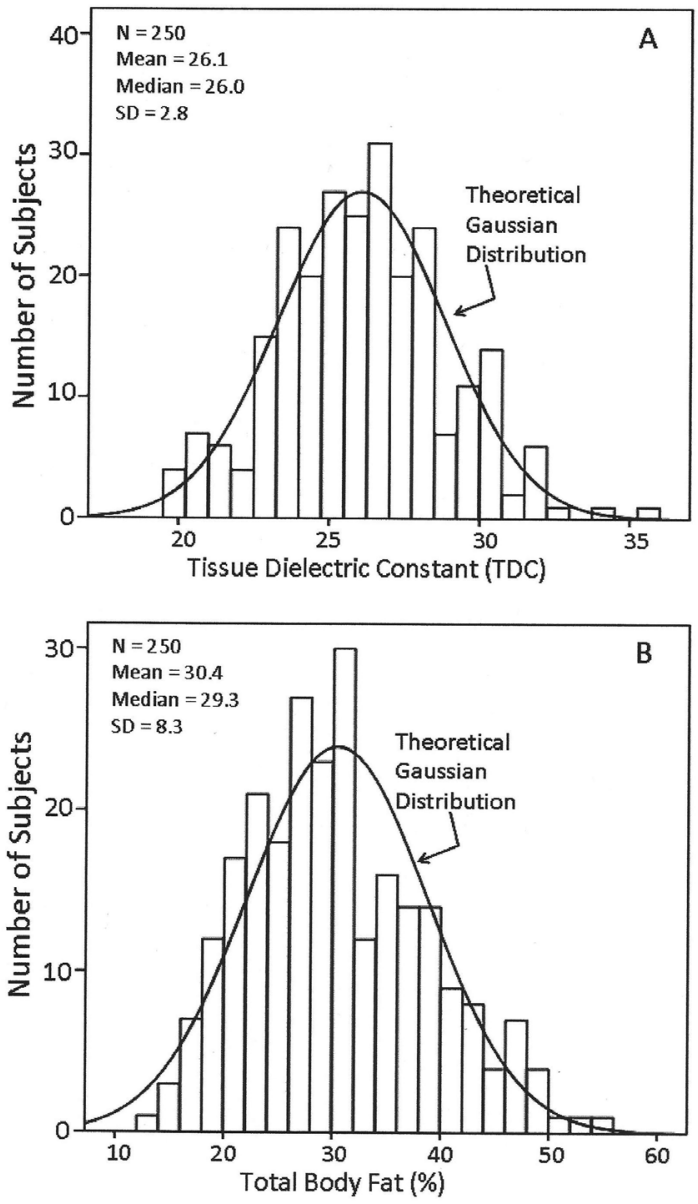

Figure 1. Tissue Dielectric Constant (TDC) Total Body Fat Percentage (TBF) Distributions. TDC values are the average obtained from dominant and nondominant arms. TDC values shown in [A] are normally distributed. The distribution of total body fat percentages $[B]$ is not normally distributed.

group. Thus, for those subjects with TBF in the lowest quartile (TBF $<24.1 \%$ ) the nondominant arm AFP was $1.13 \pm 1.63$ greater than the dominant arm. This corresponds to a $5.2 \%$ greater fat percentage. Contrastingly, for those subjects with TBF in the upper quartile (TBF $>35.6 \%$ ), the nondominant AFP was only $1.1 \%$ greater than for the dominant arm. Tissue dielectric constant (TDC) values did not differ between dominant and nondominant arms with an overall dominant/nondominant TDC ratio of $1.006 \pm 0.070$. 


\begin{tabular}{|c|c|c|c|c|c|c|c|c|c|}
\hline \multicolumn{1}{|c|}{ TABLE 1 } \\
\multicolumn{1}{|c|}{ FAT\% } & \multicolumn{7}{c|}{ TDC } \\
\hline & $\begin{array}{c}\text { DOM } \\
\text { ARM }\end{array}$ & $\begin{array}{c}\text { NDOM } \\
\text { ARM }\end{array}$ & $\begin{array}{c}\text { ARMS } \\
\text { COM- } \\
\text { BINED }\end{array}$ & $\begin{array}{c}\text { TOTAL } \\
\text { BODY } \\
\text { FAT } \\
\text { (\%) }\end{array}$ & $\begin{array}{c}\text { DOM } \\
\text { ARM }\end{array}$ & $\begin{array}{c}\text { NDOM } \\
\text { ARM }\end{array}$ & $\begin{array}{c}\text { ARMS } \\
\text { COM- } \\
\text { BINED }\end{array}$ & $\begin{array}{c}\text { DOM/ } \\
\text { NDOM } \\
\text { RATIO }\end{array}$ & $\begin{array}{c}\text { TOTAL } \\
\text { BODY } \\
\text { WATER } \\
(\%)\end{array}$ \\
\hline AVG & 31.0 & $31.7 * *$ & 31.3 & 30.4 & 26.1 & 26.0 & 26.1 & 1.007 & 51.4 \\
\hline MEDIAN & 29.8 & 30.6 & 30.3 & 29.3 & 25.9 & 25.8 & 26.0 & 1.006 & 52.1 \\
\hline SD & 8.7 & 8.4 & 8.5 & 8.3 & 3.0 & 2.8 & 2.8 & 0.070 & 5.9 \\
\hline
\end{tabular}

Table entries are for 250 female subjects. DOM and NDOM are dominant and nondominant arms respectively. ARMS COMBINED considers both DOM and NDOM and includes 500 arm measurements. $* *$ denotes $\mathbf{p}<0.001$ vs the DOM ARM.

\section{Fat-TDC Effects}

Grouping of subjects (125 per subgroup) according to whether their total body fat percentage was below or above the overall group median $(29.3 \%, \mathrm{n}=250)$ allowed for an initial group comparison of associated TDC values. These findings were further distilled by comparing subject's TDC values between those with total body fat percentages in the lower quartile $(12.2 \%$ to $24.1 \%, n=63)$ with those who had total body fat percentages in the upper quartile (35.6\% to $54.4 \%, \mathrm{n}=63$ ). A similar sub-group comparison was done based on the median BMI $\left(22.6 \mathrm{Kg} / \mathrm{m}^{2}\right)$ and its lower quartile range $\left(14.7 \mathrm{Kg} / \mathrm{m}^{2}\right.$ to $\left.20.6 \mathrm{Kg} / \mathrm{m}^{2}, \mathrm{n}=63\right)$ versus its upper quartile range $\left(26.2 \mathrm{Kg} / \mathrm{m}^{2}\right.$ to $44.3 \mathrm{Kg} / \mathrm{m}^{2}, \mathrm{n}=63$ ). These results, as reported in Table 2, show a small (0.88 TDC units) statistically significant $(\mathrm{p}=0.006)$ lower TDC value for subjects whose TBF was above the median. The comparison between lower and upper quartiles of TBF also showed a lesser value for those in the upper quartile (1.3 TDC units, $p=0.007)$. This difference corresponds to an approximately $3.3 \%$ lesser TDC value for persons above the median TBF and about 5\% lesser TDC values for persons in the upper quartile of TBF. Similar comparisons using the BMI as a cut-point revealed no significant differences in absolute TDC values between persons with total body fat percentages that were low vs. high.

\section{DISCUSSION}

The principal goal of the present research was to assess the degree to which body fat levels and body mass index might affect measured tissue dielectric constant values because such TDC measurements are used to detect, access, and track breast cancer treatment-related lymphedema (BCRL). The focus on the possible role of fat levels and BMI influencing such measurements derives from the fact that BMI and obesity are disproportionately present in women who develop breast cancer and subsequently lymphedema. Further, during treatment for acquired lymphedema or evaluations made at various times post-surgery, changes in TBF or BMI may occur the impact of which on TDC measures was not known. To supply basic information bearing on this issue a wide range of total body fat percentages (TBF) was determined in a large number of women (250) who were free of lymphedema.

The choice to evaluate healthy women rather than women with BCRL was based on two main considerations. Firstly, it was important to have a sufficiently large range of TBF values to provide suitable comparison ranges. Herein a three-fold range 


\begin{tabular}{|c|c|c|c|c|c|c|}
\hline \multicolumn{7}{|c|}{$\begin{array}{c}\text { TABLE } 2 \\
\text { TDC Values Stratified by TBF and BMI }\end{array}$} \\
\hline & \multicolumn{6}{|c|}{ Total Body Fat Percentage (TBF) } \\
\hline & $\begin{array}{l}\text { Below } \\
\text { Median }\end{array}$ & $\begin{array}{l}\text { Above } \\
\text { Median }\end{array}$ & $\begin{array}{l}\text { p- } \\
\text { value }\end{array}$ & $\begin{array}{l}\text { Lower } \\
\text { Quartile }\end{array}$ & $\begin{array}{l}\text { Upper } \\
\text { Quartile }\end{array}$ & $\begin{array}{l}\text { p- } \\
\text { value }\end{array}$ \\
\hline $\begin{array}{l}\text { Absolute } \\
\text { TDC }\end{array}$ & $26.5 \pm 2.7$ & $25.6 \pm 2.8$ & 0.006 & $26.9 \pm 2.6$ & $25.6 \pm 2.9$ & 0.007 \\
\hline \multirow[t]{3}{*}{ TDC Ratio } & $1.010 \pm 0.062$ & $1.003 \pm 0.077$ & 0.316 & $1.003 \pm 0.063$ & $0.999 \pm 0.078$ & 0.586 \\
\hline & \multicolumn{6}{|c|}{ Body Mass Index (BMI) } \\
\hline & $\begin{array}{l}\text { Below } \\
\text { Median }\end{array}$ & $\begin{array}{l}\text { Above } \\
\text { Median }\end{array}$ & $\begin{array}{l}\text { p- } \\
\text { value }\end{array}$ & $\begin{array}{l}\text { Lower } \\
\text { Quartile }\end{array}$ & $\begin{array}{l}\text { Upper } \\
\text { Quartile }\end{array}$ & $\begin{array}{l}\text { p- } \\
\text { value }\end{array}$ \\
\hline $\begin{array}{l}\text { Absolute } \\
\text { TDC }\end{array}$ & $26.0 \pm 2.6$ & $26.1 \pm 2.9$ & 0.932 & $26.4 \pm 2.7$ & $25.5 \pm 3.0$ & 0.088 \\
\hline TDC Ratio & $1.012 \pm 0.064$ & $1.002 \pm 0.075$ & 0.287 & $1.006 \pm 0.065$ & $1.001 \pm 0.078$ & 0.873 \\
\hline
\end{tabular}

Entries are mean \pm SD values for absolute TDC and dominant/nondominant side TDC ratios. Subgroups are for subjects below and above median values $(n=125$ /group) and below and above lower and upper quartiles ( $n=63$ per group). Statistical comparisons between groups are based on the Mann-Whitney test. Median TBF is $29.3 \%$. Upper and lower thresholds for lower and upper quartiles are $24.1 \%$ and $35.6 \%$ respectively. Median BMI is $22.6 \mathrm{Kg} / \mathrm{m}^{2}$. Upper and lower thresholds for lower and upper quartiles are $20.6 \mathrm{Kg} / \mathrm{m}^{2}$ and $26.2 \mathrm{Kg} / \mathrm{m}^{2}$ respectively.

$\left(14.7 \mathrm{Kg} / \mathrm{m}^{2}\right.$ to $\left.44.3 \mathrm{Kg} / \mathrm{m}^{2}\right)$ has been incorporated and evaluated. Secondly, it was important to be able to assess the dependence of interarm TDC ratios on TBF because this ratio is widely used to assess unilateral lymphedema. Such an assessment would not be possible if BCRL was already present.

One new finding demonstrated in this report is that absolute TDC values, measured to an effective depth of $2.5 \mathrm{~mm}$ on the anterior forearm, are slightly reduced in persons with higher TBF levels. Since similar measurement depths and anatomical sites are often used for assessments (30), this is a relevant finding. The magnitude of the effect is relatively small, being 1.3 TDC units at most or about $5 \%$ less than that measured in women with low-TBF. So, this difference is unlikely to be clinically important when tracking lymphedema changes in patients since there would need to be very large changes in a woman's TBF for such TBC changes to meaningfully effect sequential TDC measurements. However, there may be situations in which absolute TDC values are being compared between groups where the
TBF effect may need to be considered. The fact that TDC values are not significantly affected by BMI but are (slightly) affected by TBF likely indicates that there is more dependence on body composition than simply weight and height.

A second new finding demonstrated that inter-arm TDC ratios were essentially independent of a woman's TBF. To some extent this may have been an outcome that could have been predicted since it could have been hypothesized that both arms would have similar fat levels thereby rendering the ratio non-affected. However, as shown herein, there is a statistically significant difference in arm fat percentages with the dominant arm having slightly less fat. However, this small difference in arm fat percentage $(0.7 \%)$ was apparently too small to impact the inter-arm TDC ratio. The above findings apply specifically to the depth and site herein measured although other sites and depths may have similar features.

In conclusion, the present data suggest that when tracking lymphedema changes using the tissue dielectric constant method, 
possible temporal changes in a woman's total body fat percentage or body mass index are unlikely to significantly impact either absolute TDC values or their inter-arm ratios.

\section{ACKNOWLEDGMENTS}

The author acknowledges and thanks the many study participants without whom this research could not have come to fruition. In addition, the author wishes to acknowledge the outstanding technical prowess and dedication of Madeline Fasen, Maria Labra and Jennifer Wong who made various important contributions to this research.

\section{CONFLICT OF INTEREST AND DISCLOSURE}

The author declares no competing financial interests exist.

\section{REFERENCES}

1. WBandera, EV, U Chandran, CC Hong, et al: Obesity, body fat distribution, and risk of breast cancer subtypes in African American women participating in the AMBER Consortium. Breast Cancer Res. Tr. 150 (2015), 655666.

2. Dietze EC, Chavez TA,Seewaldt VL. Obesity and triple-negative breast cancer: Disparities, controversies, and biology. Am. J. Pathol. 188 (2018), 280-290.

3. Engin, A: Obesity-associated breast cancer: Analysis of risk factors. Adv. Exp. Med. Biol. 960 (2017), 571-606.

4. Feola, A, S Ricci, S Kouidhi, et al: Multifaceted breast cancer: The molecular connection with obesity. J. Cell Physiol. 232 (2017), 69-77.

5. Nguyen, TT, TL Hoskin, EB Habermann, et al: Breast cancer-related lymphedema risk is related to multidisciplinary treatment and not surgery alone: Results from a large cohort study. Ann. Surg. Oncol. 24 (2017), 2972-2980.

6. Ribeiro Pereira, ACP, RJ Koifman, A Bergmann: Incidence and risk factors of lymphedema after breast cancer treatment: 10 years of follow-up. Breast 36 (2017), 67-73.

7. Rohan, TE, M Heo, L Choi, et al: Body fat and breast cancer risk in postmenopausal women: A longitudinal study. J. Cancer Epidemiol. 2013 (2013), 754815.
8. Mayrovitz, HN, DN Weingrad, S Davey: Tissue dielectric constant (TDC) measurements as a means of characterizing localized tissue water in arms of women with and without breast cancer treatment related lymphedema. Lymphology 47 (2014), 142-150.

9. Mayrovitz, HN, DN Weingrad, L Lopez: Tissue dielectric constant (TDC) as an index of skin water in women with and without breast cancer: Upper limb assessment via a self-contained compact measurement device. Lymphology 49 (2016), 27-35.

10. Birkballe, $S$, MR Jensen, $S$ Noerregaard, et al: Can tissue dielectric constant measurement aid in differentiating lymphoedema from lipoedema in women with swollen legs? Br. J. Dermatol. 170 (2014), 96-102.

11. Mayrovitz, HN, M Fasen, P Spagna, et al: Role of handedness on forearm skin tissue dielectric constant (TDC) in relation to detection of early-stage breast cancer-related lymphedema. Clin. Physiol. Funct. Imaging 38 (2018), 670675.

12. Mayrovitz, $\mathrm{HN}$ : Assessing lymphedema by tissue indentation force and local tissue water. Lymphology 42 (2009), 88-98.

13. Mayrovitz, HN, S Davey: Changes in tissue water and indentation resistance of lymphedematous limbs accompanying low level laser therapy (LLLT) of fibrotic skin. Lymphology 44 (2011), 168-177.

14. Mayrovitz, HN, S Davey, E Shapiro: Localized tissue water changes accompanying one manual lymphatic drainage (MLD) therapy session assessed by changes in tissue dielectric constant inpatients with lower extremity lymphedema. Lymphology 41 (2008), 87-92.

15. Pigott, A, J Nixon, J Fleming, et al: Head and neck lymphedema management: Evaluation of a therapy program. Head Neck 40 (2018), 1131-1137.

16. Tugral, A, T Viren, Y Bakar: Tissue dielectric constant and circumference measurement in the follow-up of treatment-related changes in lower-limb lymphedema. Int. Angiol. 37 (2018), 26-31.

17. Harrow, JH, HN Mayrovitz: Subepidermal moisture surrounding pressure ulcers in persons with a spinal cord injury: A pilot study. J. Spinal Cord Med. 37 (2014), 719-728.

18. Mayrovitz, HN, SR Gildenberg, P Spagna, et al: Characterizing the tissue dielectric constant of skin basal cell cancer lesions. Skin Res. Technol. 4 (2018), 686-691.

19. Mayrovitz, HN, I Volosko, B Sarkar, et al: Arm, leg, and foot skin water in persons with diabetes mellitus (DM) in relation to hba1c assessed by tissue dielectric constant (TDC) 
technology measured at $300 \mathrm{MHz}$. J. Diabetes Sci. Technol. 11 (2017), 584-589.

20. Toyooka, KT, H Niwa, E Hashiba, et al: Can tissue dielectric constant measurements assess circulating blood volume changes in patients undergoing haemodialysis? Clin. Physiol. Funct. Imaging 38 (2017), 497-501.

21. Mayrovitz, HN, K Corbitt, A Grammenos, et al: Skin indentation firmness and tissue dielectric constant assessed in face, neck, and arm skin of young healthy women. Skin Res. Technol. 23 (2017), 112-120.

22. Mayrovitz, HN, A Grammenos, K Corbitt, et al: Young adult gender differences in forearm skin-to-fat tissue dielectric constant values measured at $300 \mathrm{MHz}$. Skin Res. Technol. 22 (2016), 81-88.

23. Mayrovitz, HN, A Singh, S Akolkar: Age-related differences in tissue dielectric constant values of female forearm skin measured noninvasively at $300 \mathrm{MHz}$. Skin Res. Technol. 22 (2016), 189-195.

24. Aimoto, A, T Matsumoto: Noninvasive method for measuring the electrical properties of deep tissues using an open-ended coaxial probe. Med. Eng. Phys. 18 (1996), 641-646.

25. Nuutinen, J, R Ikaheimo, T Lahtinen: Validation of a new dielectric device to assess changes of tissue water in skin and subcutaneous fat. Physiol. Meas. 25 (2004), 447-454.

26. Mayrovitz, HN, DN Weingrad, L Lopez: Patterns of temporal changes in tissue dielectric constant as indices of localized skin water changes in women treated for breast cancer: a pilot study. Lymphat. Res. Biol. 13 (2015), 20-32.
27. Mayrovitz, HN, DN Weingrad, L Lopez: Assessing localized skin-to-fat water in arms of women with breast cancer via tissue dielectric constant measurements in pre- and post-surgery patients. Ann. Surg. Oncol. 22 (2015), 1483-1489.

28. Alanen, E, T Lahtinen, J Nuutinen: Variational formulation of open-ended coaxial line in contact with layered biological medium. IEEE Trans. Biomed. Eng. 45 (1998), 1241-1248.

29. Athey, TW, MA Stuchly, SS Stuchly: Measurement of radio frequency permittivity of biological tissues with an open-ended coaxial line: Part I. IEEE Trans. MTT 30 (1982), 82-86.

30. Lahtinen, T, J Seppala, T Viren, et al: Experimental and analytical comparisons of tissue dielectric constant (TDC) and bioimpedance spectroscopy (BIS) in assessment of early arm lymphedema in breast cancer patients after axillary surgery and radiotherapy. Lymphat. Res. Biol. 13 (2015), 176-185.

\author{
Harvey N. Mayrovitz, PhD \\ College of Medical Sciences \\ Nova Southeastern University \\ 3200 S. University Drive \\ Davie, FL 33328 \\ mayrovit@nova.edu
}

